\title{
Phosphate binders as a cause of hypothyroidism in dialysis patients: practical indications from a review of the literature
}

Emanuela Cataldo ${ }^{1,3}$, Valeria Columbano ${ }^{1,2}$, Louise Nielsen ${ }^{1}$, Lurlynis Gendrot ${ }^{1}$, Bianca Covella ${ }^{1,3}$ and Giorgina Barbara Piccoli ${ }^{1,4^{*}}$ (D)

\begin{abstract}
Background: Although fatigue is common in dialysis patients, polypharmacy is seldom listed among its causes. In this report, we describe a dialysis patient who developed severe fatigue due to pharmacological interaction between two commonly prescribed drugs, phosphate binders and levothyroxine.

Case Presentation: A 65-year old woman, on dialysis for 17 years, complained of fatigue (weight $54 \mathrm{Kg}$, height $1.55 \mathrm{~m}$, BMI: $23 \mathrm{Kg} / \mathrm{m} 2$; malnutrition inflammation index: 10; Charlson index 9). She had been treated with lithium for about 20 years. A heavy smoker, she was obese and diabetic when young, but stopped treatment after weight loss. She had undergone thyroidectomy for papillary carcinoma, left hemicolectomy for colon adenocarcinoma, left quadrantectomy followed by radiotherapy for ductal mammary adenocarcinoma, subtotal parathyroidectomy for tertiary hyperparathyroidism. At the time of this report, she was on thrice-weekly hemodiafiltration (Daugirdas $2 \mathrm{Kt} / \mathrm{V}: 1$. 6-1.8). Her recent treatment included spironolactone, amlodipine, perindopril, valproate, lamotrigine, levothyroxine, vitamin D, calcium carbonate, sodium polystyrene and sevelamer. After she questioned her doctor about whether her fatigue might be the result of a drug interaction, levothyroxine interference was identified (TSH, previously normal, increased to $13.07 \mathrm{mU} / \mathrm{L}$, after increasing sevelamer dose, and normalized after change of drug schedule). Literature review: only 5 relevant papers on levothyroxine and phosphate binders on dialysis were found on Pubmed and EMBASE (out of 351 titles retrieved). Information was therefore inferred from studies in normal volunteers or in other diseases.

Discussion and conclusions: Our case differs from other reports on lower TSH at diagnosis, underlining the need for awareness of the importance of early diagnosis. Integrating the scant literature on dialysis patients with data available in the general population, some working conclusions can be reached: while all phosphate binders potentially interfere with levothyroxine absorption, interference seems to be highest for sevelamer; interference is limited but not excluded by increasing the intervals between drugs; morning fast is usually indicated but, when clashing with the timing of other drugs, a bedtime dose and liquid preparations may be indicated. In the absence of an agreed control schedule, our case supports close monitoring of TSH (1-3 months if unstable, twice-yearly in stable patients).
\end{abstract}

Keywords: Hemodialysis, Polypharmacy, Levothyroxine, Phosphate binders, Fatigue

\footnotetext{
* Correspondence: gbpiccoli@yahoo.it

'Néphrologie Centre Hospitalier le Mans, Avenue Roubillard, 72000, Le Mans,

France

${ }^{4}$ Dipartimento di Scienze Cliniche e Biologiche, Università di Torino, Turin,

Italy

Full list of author information is available at the end of the article
}

(c) The Author(s). 2018 Open Access This article is distributed under the terms of the Creative Commons Attribution 4.0 International License (http://creativecommons.org/licenses/by/4.0/), which permits unrestricted use, distribution, and reproduction in any medium, provided you give appropriate credit to the original author(s) and the source, provide a link to the Creative Commons license, and indicate if changes were made. The Creative Commons Public Domain Dedication waiver (http://creativecommons.org/publicdomain/zero/1.0/) applies to the data made available in this article, unless otherwise stated. 


\section{Background}

Fatigue is a debilitating symptom very often experienced by patients undergoing dialysis [1-3].

In this context, fatigue can have a variety of causes, such as anemia, the malnutrition inflammatory syndrome, nutritional deficits, insufficient dialysis, fluid overload, depression and chronic pain [1-7]. Despite the increasing interest in reducing the number of drugs taken by chronic dialysis patients, polypharmacy is seldom listed among the common causes of fatigue.

In this report, we describe a patient on chronic dialysis who developed severe fatigue due to pharmacological interaction between two drugs commonly prescribed for dialysis patients: phosphate binders and thyroid hormone replacement therapy.

Patients with end-stage renal disease (ESRD) exhibit various changes in thyroid function: according to some studies, between 10 and $25 \%$ of dialysis patients have some kind of thyroid derangement [8-12]. Hypothyroidism accounts for most of these cases [8-12].

Levothyroxine is therefore commonly used to treat ESRD patients (estimated as used by 2 to $10 \%$ of these patients) and, while it is well known that many drugs and foods interfere with its absorption, no study has analyzed the multiple potential interferences in patients on chronic hemodialysis, who are typically on a complex polypharmacy $[13,14]$.

Hence, the case described in this study provided an opportunity to review the literature and draw some practical conclusions regarding the interferences between levothyroxine and phosphate binders, the drugs most commonly used by dialysis patients. The description of the case is followed by a systematic review of the literature on the interference between levothyroxine and phosphate binders in dialysis patients, integrated wherever possible by data obtained on non-dialysis patients, making it possible to offer a reasoned guide to prescription, while highlighting the limits of the current evidence.

\section{Case Presentation}

A 65-year old woman, on dialysis for 17 years, told her doctor she was exhausted and that she thought it was because she was taking too many drugs. The patient is an intelligent, independent, acculturated woman who lives alone in the French countryside.

Her medical history is complex: she was treated with lithium for about 20 years (from age 20 to 40). This was discontinued after she developed CKD; in recent years, under treatment with valproic acid and lamotrigine, her psychophysical balance has been good,

She started smoking when she was 19 years old (30 cigarettes/day) and developed a smoke-related chronic obstructive pulmonary disease. She was obese in early adulthood; arterial hypertension was diagnosed at age 30 and type 2 diabetes at age 32, treated using oral hypoglycemic drugs, but she eventually lost about $20 \mathrm{~kg}$, making it possible for antidiabetic drugs to be discontinued. She underwent total thyroidectomy for papillary carcinoma at age 41, and started levothyroxine therapy afterwards. Due to a progressive worsening of the kidney function she started hemodialysis at age 50 . Her kidney disease was probably multifactorial (hypertension, diabetes, obesity, heavy smoking, lithium therapy).

Seven years after dialysis start, she underwent left hemicolectomy for colon adenocarcinoma, and two years later, left quadrantectomy followed by radiotherapy for ductal mammary adenocarcinoma. She underwent subtotal parathyroidectomy for severe tertiary hyperparathyroidism at age 62. Due to the presence of severe scoliosis, and the development of peripheral neuropathy, she uses painkillers regularly.

At the time of the present report, she was on thriceweekly hemodiafiltration, with good dialysis tolerance and high dialysis efficiency (Daugirdas $2 \mathrm{Kt} / \mathrm{V}: 1.6-1.8$ ).

Her most recent treatment included antihypertensive drugs (spironolactone $100 \mathrm{mg}$, amlodipine $20 \mathrm{mg}$, perindopril $2.5 \mathrm{mg}$ ), antipsychotic drugs (valproic acid $600 \mathrm{mg}$, lamotrigine $100 \mathrm{mg}$ ), thyroid hormone (levothyroxine $150 \mu \mathrm{g})$, vitamin D, bicarbonate and calcium supplements (calcium carbonate $1 \mathrm{~g}$, sodium bicarbonate $500 \mathrm{mg}$, vitamin D 25-OH 100,000 UI once a month), potassium and phosphate binders (sodium polystyrene sulphonate, on non-dialysis days and sevelamer $2.4 \mathrm{~g}$ per day), darbopoietin $20 \mu \mathrm{cg}$ once weekly.

The clinical examination revealed a woman with good psychophysical balance, a moderate impairment in nutritional status, and a severe comorbidity burden (weight $54 \mathrm{Kg}$, height 155, BMI: $23 \mathrm{Kg} / \mathrm{m} 2$; subjective global assessment: B; malnutrition inflammation index: 10; Charlson index: 9). Apart from signs of chronic bronchitis, and an aortic 2/6 heart bruit, the clinical examination was unremarkable; arterial blood pressure was $150 / 90 \mathrm{mmHg}$, with mild orthostatic hypotension $(135 / 80 \mathrm{mmHg})$; heart rate was $68 \mathrm{bpm}$. The most recent biochemical results are reported in Table 1.

The patient complained of severe fatigue, which had recently increased, and asked her doctor if he thought this could be the result of taking too many drugs.

In fact we thought our patient was right about pharmacologic interference, and felt that levothyroxine was the most likely candidate. A biochemical control disclosed a relevant increase in TSH $(13.07 \mathrm{mU} / \mathrm{L})$, as compared with her previous routine twice-yearly control (4.14 mU/L).

In retrospect, the levothyroxine dose was already high for a woman weighing about $55 \mathrm{Kg}$, and a reduction in the absorption of levothyroxine should already have been suspected.

Three of her chronic drugs display potential interference with levothyroxine: calcium carbonate, sevelamer 
Table 1 Main biochemical data in our patient

\begin{tabular}{llll}
\hline & Month 1 & Month 2 & Diagnosis (month 3) \\
\hline Hemoglobin g/dl & 14.5 & 11.5 & 11.5 \\
Urea predialysis mg/dl & 159.03 & 160.84 & 131.92 \\
Kt/N & 1.78 & 1.59 & 1.55 \\
Creatinine mg/dl & 7.96 & 7.85 & 6.33 \\
Na mmol/l & 142 & 145 & 145 \\
K mmol/l & 4.8 & 4.7 & 4.5 \\
Colesterol mg/dl & 200 & 164 & - \\
Albumin g/l & 34 & 34 & 34 \\
Total proteins g/l & 73 & 70 & 72 \\
CRP mg/l & 10 & $<4$ & $<4$ \\
BNP pg/ml & 242 & 202 & 340 \\
Transferrin mg/dl & 206 & 206 & 225 \\
PTH ng/l & 92 & 181 & 199 \\
Vitamin D $\mu \mathrm{gg} / \mathrm{l}$ & 51 & 52 & 64 \\
Ca mg/dl & 10.12 & 8.24 & 8.12 \\
Phosphate mg/dl & 9.64 & 9.11 & 6.75 \\
\hline
\end{tabular}

Legend: $B N P$ blood natriuretic peptide; CRP C- reactive protein; $P T H$ parathyroid hormone

and kayexelate. Since her sevelamer dose had recently been increased from $800 \mathrm{mg}$ once daily to $800 \mathrm{mg} 3$ times per day, this long-scting phosphate binder was the most likely candidate. In keeping with this hypothesis, one month after discontinuation of sevelamer and modification of the timing of levothyroxine treatment (in the morning after night fasting) TSH was once more in the normal range. In the three months that followed, her levothyroxine dose was reduced to 100 micrograms per day. A further attempt to reintroduce sevelamer, taken at least $6 \mathrm{~h}$ after levothyroxine, led to a new increase in TSH (TSH $12.66 \mathrm{mUI} / \mathrm{l})$, once more corrected by discontinuation of sevelamer.

\section{Systematic review of the literature}

Pubmed and EMBASE were explored (start to February 15th 2018) with the aim of retrieving papers related to dialysis, levothyroxine and phosphate binders. The following terms were employed: (a) dialysis, hemodialysis, hemodiafiltration, renal replacement therapy; (b) phosphate binder(s), sevelamer, calcium carbonate, calcium acetate, aluminum hydroxide, lanthanum carbonate; (c) levothyroxine, thyroid hormone replacement therapy. Due to the low number of papers retrieved by this search, a further search was performed combining (b) and (c). The searches, paper selection and data extraction were performed in duplicate (EC and VC); a further search on Google med did not lead to further papers. Discrepancies were resolved by discussion with a third party (GBP). A manual search of the reference lists from identified articles was done to identify additional articles. The search strategy and flow-chart is reported in Fig. 1.

Given the small number of papers retrieved, and their high heterogeneity, a meta-analysis was not performed, and the data were narratively discussed, in relation to other sources of information (data obtained in healthy volunteers, or in other diseases).

\section{Discussion and conclusions}

Many physiological and pathological conditions can alter levothyroxine absorption [15-17].

In addition to gastrointestinal diseases, from gastritis to helicobacter infection, inflammatory bowel disease and intestinal infections, and malabsorption, several foods and beverages (including dietary fibers, soybeans, herbal remedies, papaya, grapefruit, and coffee) affect the absorption of levothyroxine [15].

However, in patients on polypharmacy, pharmacological interferences are the major cause of levothyroxine malabsorption [15-18]. Several drugs are listed; the effect is usually higher when taken simultaneously or less than one hour before or after taking levothyroxine. The potential list in dialysis patients is long, and includes gastro-protective agents, antibiotics, bile acid sequestrants, oral iron, potassium binders (sodium polystyrene sulphonate) and, most importantly, phosphate binders [15-18].

Phosphate binders are probably the drug most widely used by dialysis patients and virtually all phosphate binders interfere with levothyroxine absorption. These include aluminum hydroxide, calcium salts (calcium carbonate, calcium citrate and calcium acetate), sevelamer, magnesium hydroxide, lantanum carbonate and sucrofferic oxyhydroxide [19-32].

The mechanism of phosphate binding is different. Some agents use ionic interactions to attract, bind and precipitate phosphate; the insoluble phosphate compound is ultimately excreted in the feces.

Aluminum hydroxide, calcium salts, magnesium hydroxide, and lantanum carbonate are inorganic salts which release ions that trap dietary phosphate in the gut. Sucrofferic oxyhydroxide, instead, is a new compound containing an iron (III)-oxyhydroxide core which binds phosphate in the intestinal lumen [29,30]. Sevelamer is different from the other phosphate binders because as it is composed of a cationic hydrogel with multiple amine groups which become protonated in the gastrointestinal tract and bind with anionic phosphate and other anionic substances, including certain drugs, interfering with their absorption [32]. This may explain the higher number of pharmacological interactions described with sevelamer.

While we know that pharmacokinetics and binding avidity often differ, most of the available data were obtained in cohorts that are clinically different from dialysis patients. 
Additional records identified through reference lists $(n=8)$

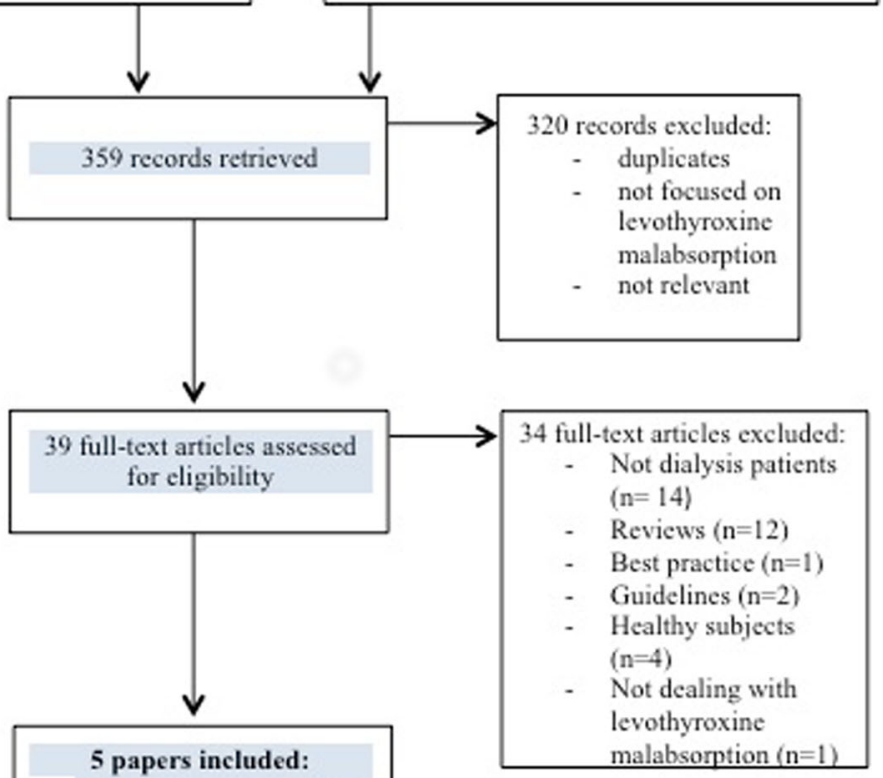

5 papers included:

case reports: $n=4$

- case series: $\mathbf{n}=1$

Fig. 1 Search strategy and selection of papers

For instance, the interference between calcium supplements and levothyroxine absorption has mainly been studied in post-menopausal women [21, 22, 24-27]. Moreover, in some studies other interfering drugs were excluded $[16,21,23,30,31,33]$. Data on the interference between levothyroxine absorption and the phosphate binders specifically used in dialysis patients are derived principally from studies using healthy volunteers $[16,23,30,33]$.
Therefore, the indications on treatment modalities were obtained in settings that are profoundly different from the complex polypharmacy of dialysis patients, a population in which malnutrition, malabsorption, gastropathy and diabetic neuropathy often play a relevant role in modifying absorption [15, 34-36].

Our review of the literature, which focused on the evidence specifically related to dialysis patients, retrieved

Table 2 Papers on levothyroxine malabsorption in dialysis patients taking phosphate binders, retrieved after a systematic review of the literature

\begin{tabular}{|c|c|c|c|c|c|c|c|c|}
\hline Author (reference) & $n$ & Study design & Age & $\begin{array}{l}\text { RRT Vintage } \\
\text { (years) }\end{array}$ & $\begin{array}{l}\text { Phosphate } \\
\text { binder(s) }\end{array}$ & $\begin{array}{l}\text { TSH } \\
\mathrm{mU} / \mathrm{L}\end{array}$ & Associated drugs & Therapeutic measures \\
\hline lovino 2014 [21] & 1 & Case report & 26 & 2 & Sevelamer & 650 & $\begin{array}{l}\text { No potentially interfering } \\
\text { drugs }\end{array}$ & $\begin{array}{l}\text { Sevelamer at least } 4 \mathrm{~h} \text { after } \\
\text { laevothyroxyne }\end{array}$ \\
\hline Wong, 2012 [32] & 1 & Case report & 30 & 12 & Sevelamer & $\sim 600$ & Not reported & $\begin{array}{l}\text { Switch to sublingual } \\
\text { levothyroxine. } \\
\text { Sevelamer far from } \\
\text { levothyroxine }\end{array}$ \\
\hline Granata, 2011 [30] & 1 & Case report & 55 & 3 & Sevelamer & 153 & Ramipril, Pantoprazole & $\begin{array}{l}\text { Levothyroxine } 2 \mathrm{~h} \text { after } \\
\text { dinner }\end{array}$ \\
\hline Arnadottir 2007 [31] & 1 & Case report & 62 & NA & Sevelamer & 297 & $\begin{array}{l}\text { Amlodipine, Enalapril, } \\
\text { Esomeprazol, Paracetamol, } \\
\text { Vitamins }\end{array}$ & $\begin{array}{l}\text { Levothyroxine at night, at } \\
\text { least } 4 \mathrm{~h} \text { after other drugs }\end{array}$ \\
\hline Diskin, 2007 [23] & 67 & $\begin{array}{l}\text { Retro-spective } \\
\text { study }\end{array}$ & $\begin{array}{l}74.74 \\
\text { (mean) }\end{array}$ & NA & $\begin{array}{l}\text { Calcium carbonate, } \\
\text { Calcium acetate, } \\
\text { Sevelamer }\end{array}$ & $* *$ & $\begin{array}{l}\text { Patients taking interfering } \\
\text { drugs were excluded }\end{array}$ & $\begin{array}{l}\text { Changing timing of } \\
\text { levothyroxine or switching } \\
\text { to calcium acetate }\end{array}$ \\
\hline
\end{tabular}


only 5 papers, of which 4 were case reports and 1 was a case series (Fig. 1, Table 2). Based on this limited body of evidence, interference seems to be higher for sevelamer than for calcium salts, lanthanum and preparations containing aluminum [28, 31, 37-39].

The one large observational study of hemodialysis patients on levothyroxine and on different phosphate binders involved 67 individuals. It found higher TSH levels in patients on calcium carbonate and sevelamer, than in those being treated with calcium acetate [31]. However, it excluded all other "potentially interfering drugs", and its lack of information on associated therapies in the different groups of patients represents a limit of this important study [31].

Another limit of the current literature is that it does not provide evidence on the dose at which the interaction is most significant, nor it gives insight on a threshold effect. In the absence of this information, we hold that the effect is non dose dependent.

Our case differs from the other cases reported in literature in the level of TSH at diagnosis, which was over 100 in the other four case reports. In fact, in many settings, TSH is not routinely checked in dialysis patients, and, due to the clinical mimicry of hypothyroidism and dialysis-related symptoms, first of all fatigue, diagnosis may be delayed. While suggesting systematic TSH testing in all dialysis patients is beyond the scope of this report, we have tried to show that the available evidence supports its clinical management in dialysis patients on levothyroxine. Figure 2 and Table 3 summarize the answers to four questions: Which phosphate binders should be prescribed? At what time intervals should they be taken? Are there alternatives? How often should patients be monitored??

\section{Levothyroxine supplementation in dialysis patients}

\begin{tabular}{l}
\begin{tabular}{|l|l|}
\hline 1. Choose phosphate binder: \\
\hline SEVELAMER & $\begin{array}{l}\text { Probably the highest binding effect on levothyroxine. } \\
\text { The most frequently described interference in levothyroxine } \\
\text { absorption (perhaps due to its wide use in dialysis) }\end{array}$ \\
\hline CALCIUM SALTS & $\begin{array}{l}\text { The highest interference is described for calcium carbonate. } \\
\text { Contrasting data for calcium acetate (probably lower interference). }\end{array}$ \\
\hline ALUMINIUM HYDROXIDE & Few data. Less frequently used now than in the past. \\
\hline LANTHANUM CARBONATE & Few data. Interference described in 6 healthy subjects. \\
\hline $\begin{array}{l}\text { SUCROFERRIC } \\
\text { OXYHYDROXIDE }\end{array}$ & Novel phosphate binder. No data available in dialysis patients. \\
\hline
\end{tabular} \\
\hline
\end{tabular}

\begin{tabular}{|l|l|}
\hline POTASSIUM BINDERS & $\begin{array}{l}\text { Known to roduce absorption of levothyroxine, but entity is not clear, little } \\
\text { information on new binders (patiromer, and sodium zironium cyclosilicate) }\end{array}$ \\
\hline IRON PREPARATIONS & $\begin{array}{l}\text { Interaction widely described in the literature. Less frequent in hemodialysis } \\
\text { due to the use of intravenous iron. }\end{array}$ \\
\hline PROTON POMIP INHIBITORS & Contrasting data. H2-receptor antagonists nrobably less interfering \\
\hline BILE ACID SEQUESTRANTS & $\begin{array}{l}\text { Known to reduce absorption of levothyroxine, but level of interaction } \\
\text { is not clear }\end{array}$ \\
\hline ANTIBIOTICS & $\begin{array}{l}\text { Reduction of absorption described for ciprofloxacin. } \\
\text { Contrasting data for rifampicin (possible increase in absorption) }\end{array}$ \\
\hline
\end{tabular}

\begin{tabular}{|l|}
\hline 3. Timing of Levothyroxine - shift to liquid formulation \\
\hline $\begin{array}{l}\text { Administration of levothyroxine in the moming } 30 \text { minutes before breakfast and other drugs, } \\
\text { taken only with water } \\
\text { Distance of } 2 \text { to } 4 \text { hours between levothyroxine morning dose, phosphate binders and other drugs } \\
\text { on the list }\end{array}$ \\
\hline If not possible (low compliance, polypharmacy in the morning) or if insufficient: \\
\hline Bedtime levothyroxine (at least 2 hours after meals). \\
\hline If instable values or high Levothyroxine need: \\
\hline
\end{tabular}

Fig. 2 Levothyroxine supplementation in dialysis patients: practical insights 
Table 3 Indications for controls

Controls over time:

No agreed indication

Monitoring TSH and fT4 at least every 3 months in patients on one phosphate binder + one other potentially interfering drug (on the basis of the high levels found in the previous studies, and in ours)

Monthly monitoring if unstable TSH or if new potentially interfering drugs, change in dose of phosphate binder, or more than 2 potentially interfering drugs (importance of early diagnosis)

Reduce frequency when there has been long-term stability, and no change in treatment (probably wise to monitor patient at least twice a year)

The first point is the choice of the phosphate binder. Although sevelamer seems to be the one with the highest degree of interference, in the absence of precise data, all phosphate binders should be considered to be potentially capable of interfering with levothyroxine absorption [28, 31, 37-39].

The second point regards the timing of levothyroxine administration: the standard recommendation is to take it at least 30 min before breakfast. However, this may conflict with the complex polypharmacy commonly prescribed in dialysis patients. Delayed gastric emptying, linked to diabetes or to uremia, may also play a role in retarding gastric emptying and reducing absorption [35, 36]. In line with what is known, a phosphate binder should be taken at an interval of at least two hours from levothyroxine, keeping the interval between LT4 and binding agents as constant as possible [15]. An alternative could be bedtime administration of levothyroxine, which may be favorable in particular in patients who dine early and consume their largest meal at noon, thus minimizing interferences with food [40, 41].

Several studies have shown better pharmacokinetics and bioavailability of liquid formulations and of soft gel capsules, whose faster absorption is less affected by food and drug interactions [42-45]. However, the advantage has to be balanced against the risk of errors, which is higher with drops than with pills. Furthermore, the cost of liquid formulations is higher (for example, in Italy, 0.331 euros/ day versus 0.0578 euros/day for tablets) [42].

The last question is how often patients need to be monitored. Given the absence of data on the effect of simultaneous administration of several potentially interfering drugs, we suggest a very cautious approach, in particular in potentially interfering polypharmacy, and in case of treatment or posology changes (Table 3).

In summary, this case points out the importance of pharmacological interaction in dialysis patients and suggests paying particular attention to levothyroxine in the context of polypharmacy. Our review was focused on phosphate binders, which probably represent the most commonly used drugs in dialysis patients, while other frequently used drugs, including proton-pump inhibitors and potassium binders can reduce levothyroxine absorption [15-18].

In the absence of studies addressed to the modulation of levothyroxine absorption by different combination of commonly used drugs in dialysis patients, our case provides evidence that TSH should be closely monitored at regular intervals in dialysis patients on thyroid hormone replacement therapy.

\section{Abbreviations}

BMI: Body mass index; CKD: Chronic kidney disease; ESRD: End-stage renal disease; TSH: Thyroid stimulating hormone

\section{Acknowledgements}

The authors are grateful to Susan Finnel for her careful review of the language.

Funding

The Centre Hospitalier Le Mans covers the cost of English review and publication.

Availability of data and materials

Not applicable to this case. The authors can be contacted for further information.

Authors' contributions

Authors' contributions: GBP, EC and VC drafted the case; EC and VC made the tables and the figures; EC, VC and BC retrieved the literature and extracted the data; LN and LG extracted and discussed patient data. All authors read and approved the present version.

Ethics approval and consent to participate

Not applicable

\section{Consent for publication}

The patient signed an informed consent allowing anonymous use of her data for publication and research purposes.

\section{Competing interests}

GBP is section editor of BMC Nephrology; no other conflict of interest to declare for this case report and systematic review of the literature.

\section{Publisher's Note}

Springer Nature remains neutral with regard to jurisdictional claims in published maps and institutional affiliations.

\section{Author details}

${ }^{1}$ Néphrologie Centre Hospitalier le Mans, Avenue Roubillard, 72000, Le Mans, France. 'Nefrologia, Università della Campania "Luigi Valvitelli", Naples, Italy. ${ }^{3}$ Nefrologia, Università degli Studi di Bari "Aldo Moro", Bari, Italy.

${ }^{4}$ Dipartimento di Scienze Cliniche e Biologiche, Università di Torino, Turin, Italy.

Received: 12 March 2018 Accepted: 14 June 2018

Published online: 02 July 2018

\section{References}

1. Oliver $\mathrm{V}$, Stephenson M. Prevention, assessment and management of post-dialysis fatigue in patients attending in-center hemodialysis: a best practice implementation project. JBI Database System Rev Implement Rep. 2016;14(11):278-88.

2. Covic A, Siriopol D, Voroneanu L. Dialysis-induced segmental wall motion abnormalities, post-dialysis fatigue and cardiovascular mortality: the new Bermuda triangle? Nephrol Dial Transplant. 2013;28(10):2404-6.

3. Bossola M, Vulpio C, Tazza L. Fatigue in chronic dialysis patients. Semin Dial 2011;24(5):550-5.

4. Jhamb M, Argyropoulos C, Steel JL, Plantinga L, Wu AW, Fink NE, Powe NR, Meyer KB, Unruh ML. Choices for healthy outcomes in caring for end-stage renal disease (CHOICE) study. Correlates and outcomes of fatique among incident dialysis patients. Clin J Am Soc Nephrol. 2009;4(11):1779-86. 
5. Bossola M, Marzetti E, Di Stasio E, Monteburini T, Cenerelli S, Mazzoli K, Parodi E, Sirolli V, Santarelli S, Ippoliti F, Nebiolo PE, Bonomini M, Melatti R, Vulpio C. Prevalence and associated variables of post-dialysis fatigue: Results of a prospective multicentre study. Nephrology (Carlton). 2018;23(6):552-58.

6. Picariello F, Moss-Morris R, Macdougall IC, Chilcot AJ. The role of psychological factors in fatigue among end-stage kidney disease patients: a critical review. Clin Kidney J. 2017;10(1):79-88

7. van der Borg WE, Schipper K, Abma TA. Protocol of a mixed method, randomized controlled study to assess the efficacy of a psychosocia intervention to reduce fatigue in patients with end-stage renal disease (ESRD). BMC Nephrol. 2016;17(1):73.

8. Da Costa AB, Pellizzari C, Carvalho GA, Sant'Anna BC, Montenegro RL, Zammar Filho RG, Mesa Junior CO, Hauck Prante PR, Olandoski M, Carvalho M. High prevalence of subclinical hypothyroidism and nodular thyroid disease in patients on hemodialysis. Hemodial Int. 2016;20(1):31-7.

9. Lin CC, Chen TW, Ng YY, Chou YH, Yang WC. Thyroid dysfunction and nodular goiter in hemodialysis and peritoneal dialysis patients. Perit Dial Int 1998;18(5):516-21.

10. Kaptein EM, Quion-Verde H, Chooljian CJ, Tang WW, Friedman PE, Rodriquez HJ, Massry SG. The thyroid in end-stage renal disease. Medicine (Baltimore). 1988:67(3):187-97.

11. Cuna V, Menghi V, Comai G, Cappuccilli M, Cianciolo G, Raimondi C, Grammatico F, Donati G, Baraldi O, Capelli I, LA Manna G. Functional Abnormalities and thyroid nodules in patients with end-stage renal disease. In Vivo. 2017;31(6):1203-8.

12. Lo JC, Beck GJ, Kaysen GA, Chan CT, Kliger AS, Rocco MV, Li M, Chertow GM, Study FHN. Thyroid function in end stage renal disease and effects of frequent hemodialysis. Hemodial Int. 2017;21(4):534-41.

13. McIntyre C, McQuillan R, Bell C, Battistella M. Targeted Deprescribing in an outpatient hemodialysis unit: a quality improvement study to decrease polypharmacy. Am J Kidney Dis. 2017;70(5):611-8.

14. Wright A, Lovering S, Battistella M. Deprescribing: Is there a role in hemodialysis? CANNT J. 2015;25(1):21-3; quiz 24-5.

15. Skelin M, Lucijanić T, Amidžić Klarić $D$, Rešić $A$, Bakula M, Liberati-Čizmek AM, Gharib H, Rahelić D. Factors affecting gastrointestinal absorption of levothyroxine: a review. Clin Ther. 2017:39(2):378-403.

16. Zamfirescu I, Carlson HE. Absorption of levothyroxine when coadministered with various calcium formulations. Thyroid. 2011;21(5):483-6.

17. Liwanpo L, Hershman JM. Conditions and drugs interfering with thyroxine absorption. Best Pract Res Clin Endocrinol Metab. 2009:23(6):781-92.

18. Ward LS. The difficult patient: drug interaction and the influence of concomitant diseases on the treatment of hypothyroidism. Arq Bras Endocrinol Metabol. 2010;54(5):435-42.

19. Sperber $A D$, Liel $Y$. Evidence for interference with the intestinal absorption of levothyroxine sodium by aluminum hydroxide. Arch Intern Med. 1992;152:183-4

20. Liel Y, Sperber AD, Shany S. Nonspecific intestinal adsorption of levothyroxine by aluminum hydroxide. Am J Med. 1994;97(4):363-5.

21. Singh $N$, Singh PN, Hershman JM. Effect of calcium carbonate on the absorption of levothyroxine. JAMA. 2000;283(21):2822-5.

22. Csako G, McGriff NJ, Rotman-Pikielny P, Sarlis NJ, Pucino F. Exaggerated levothyroxine malabsorption due to calcium carbonate supplementation in gastrointestinal disorders. Ann Pharmacother. 2001;35(12):1578-83.

23. Singh N, Weisler SL, Hershman JM. The acute effect of calcium carbonate on the intestinal absorption of levothyroxine. Thyroid. 2001;11(10):967-71.

24. Mazokopakis EE, Giannakopoulos TG, Starakis IK. Interaction between levothyroxine and calcium carbonate. Can Fam Physician. 2008;54(1):39.

25. Mazokopakis EE. Counseling patients receiving levothyroxine (L-T4) and calcium carbonate. Mil Med. 2006:171(11):vii. 1094

26. Butner LE, Fulco PP, Feldman G. Calcium carbonate-induced hypothyroidism. Ann Intern Med. 2000;132(7):595.

27. Schneyer CR. Calcium carbonate and reduction of levothyroxine efficacy. JAMA. 1998:279(10):750

28. lovino M, lovine N, Petrosino A, Giagulli VA, Licchelli B, Guastamacchia E. Sevelamer carbonate markedly reduces levothyroxine absorption. Endocr Metab Immune Disord Drug Targets. 2014;14(3):206-9.

29. Aaseth J, Bjørke-Monsen AL. Lanthanum carbonate - a new phosphate binding drug in advanced renal failure. Curr Med Chem 2017. https://doi.org/10.2174/ 0929867324666170509125840. [Epub ahead of print]
30. Weitzman SP, Ginsburg KC, Carlson HE. Colesevelam hydrochloride and lanthanum carbonate interfere with the absorption of levothyroxine. Thyroid. 2009;19(1):77-9.

31. Diskin CJ, Stokes TJ, Dansby LM, Radcliff L, Carter TB. Effect of phosphate binders upon TSH and L-thyroxine dose in patients on thyroid replacement. Int Urol Nephrol. 2007;39(2):599-602.

32. Perry CM, Plosker GL. Sevelamer carbonate: a review in hyperphosphatemia in adults with chronic kidney disease. Drugs. 2014;74:771-92.

33. John-Kalarickal J, Pearlman G, Carlson HE. New medications which decrease levothyroxine absorption. Thyroid. 2007;17(8):763-5.

34. Ingenbleek Y, Beckers C. Evidence for intestinal malabsorption of iodine in protein-calorie malnutrition. Am J Clin Nutr. 1973;26(12):1323-30.

35. Khraisha OS, Al-Madani MM, Peiris AN, Paul TK. Gastroparesis - a novel cause of persistent thyroid stimulating hormone elevation in hypothyroidism. J La State Med Soc. 2015;167(2):47-9.

36. Reardon DP, Yoo PS. Levothyroxine tablet malabsorption associated with gastroparesis corrected with gelatin capsule formulation. Case Reports in Endocrinology. Volume 2016, Article ID 1316724, 3 pages. https://doi.org/10. $1155 / 2016 / 1316724$

37. Granata A, Floccari F, Gallieni M. Levothyroxine and sevelamer: listen to the patient. Endocr Pract. 2011;17(6):961-2.

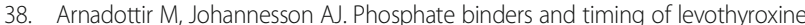
administration. Nephrol Dial Transplant. 2008;23(1):420.

39. Wong C, Codorniz K, Infante S. Noncompliance? Not Necessarily. A case of sevelamer inhibition of levothyroxine absorption. The Endocrine's society's 94th annual meeting and expo, June 23-26, 2012 - Houston, TX.

40. Bach-Huynh TG, Nayak B, Loh J, Soldin S, Jonklaas J. Timing of levothyroxine administration affects serum thyrotropin concentration. J Clin Endocrinol Metab. 2009;94(10):3905-12.

41. Bolk N, Visser TJ, Kalsbeek A, van Domburg RT, Berghout A. Effects of evening vs morning thyroxine ingestion on serum thyroid hormone profiles in hypothyroid patients. Clin Endocrinol. 2007;66(1):43-8.

42. Brancato D, Scorsone A, Saura G, Ferrara L, Di Noto A, Aiello V, Fleres M, Provenzano V. Comparison of TSH levels with liquid formulations versus tablet formulations of levothyroxine in the treatment of adult hypothyroidism. Endocr Pract. 2014;20(7):657-62

43. Vita R, Di Bari F, Benvenga S. Oral liquid levothyroxine solves the problem of tablet levothyroxine malabsorption due to concomitant intake of multiple drugs. Expert Opin Drug Deliv. 2017:14(4):467-72.

44. Fallahi P, Ferrari SM, Antonelli A. Oral L-thyroxine liquid versus tablet in patients with hypothyroidism without malabsorption: a prospective study. Endocrine. 2016:52:597-601.

45. Negro R, Valcavi R, Agrimi D, Toulis KA. Levothyroxine liquid solution versus tablet for replacement treatment in hypothyroid patients. Endocr Pract. 2014;20:901-6

\section{Ready to submit your research? Choose BMC and benefit from:}

- fast, convenient online submission

- thorough peer review by experienced researchers in your field

- rapid publication on acceptance

- support for research data, including large and complex data types

- gold Open Access which fosters wider collaboration and increased citations

- maximum visibility for your research: over $100 \mathrm{M}$ website views per year

At BMC, research is always in progress.

Learn more biomedcentral.com/submissions 